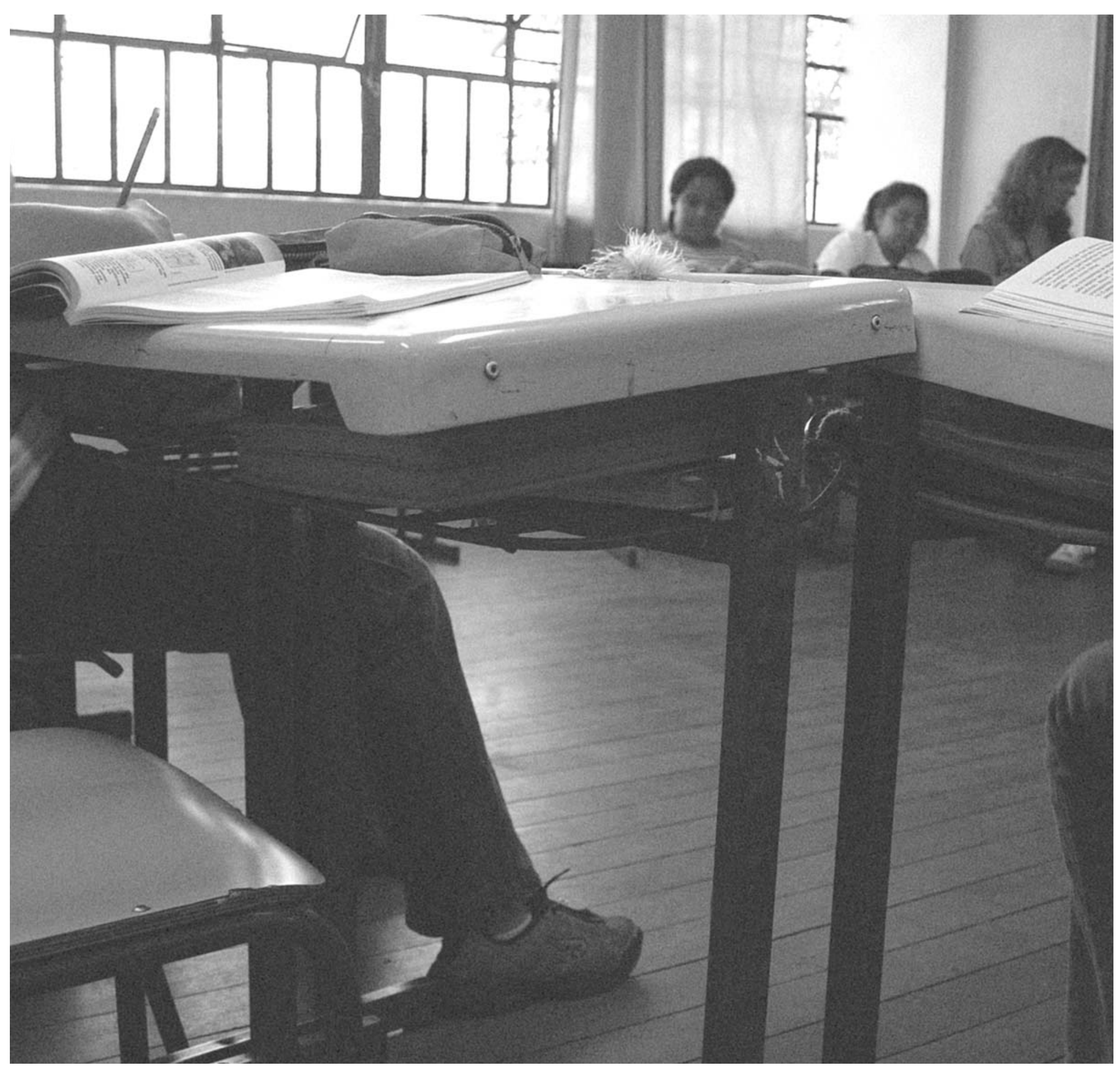




\section{Avaliando na perspectiva sociocultural}

TÂNIA REgINA de SOUZA Romero*

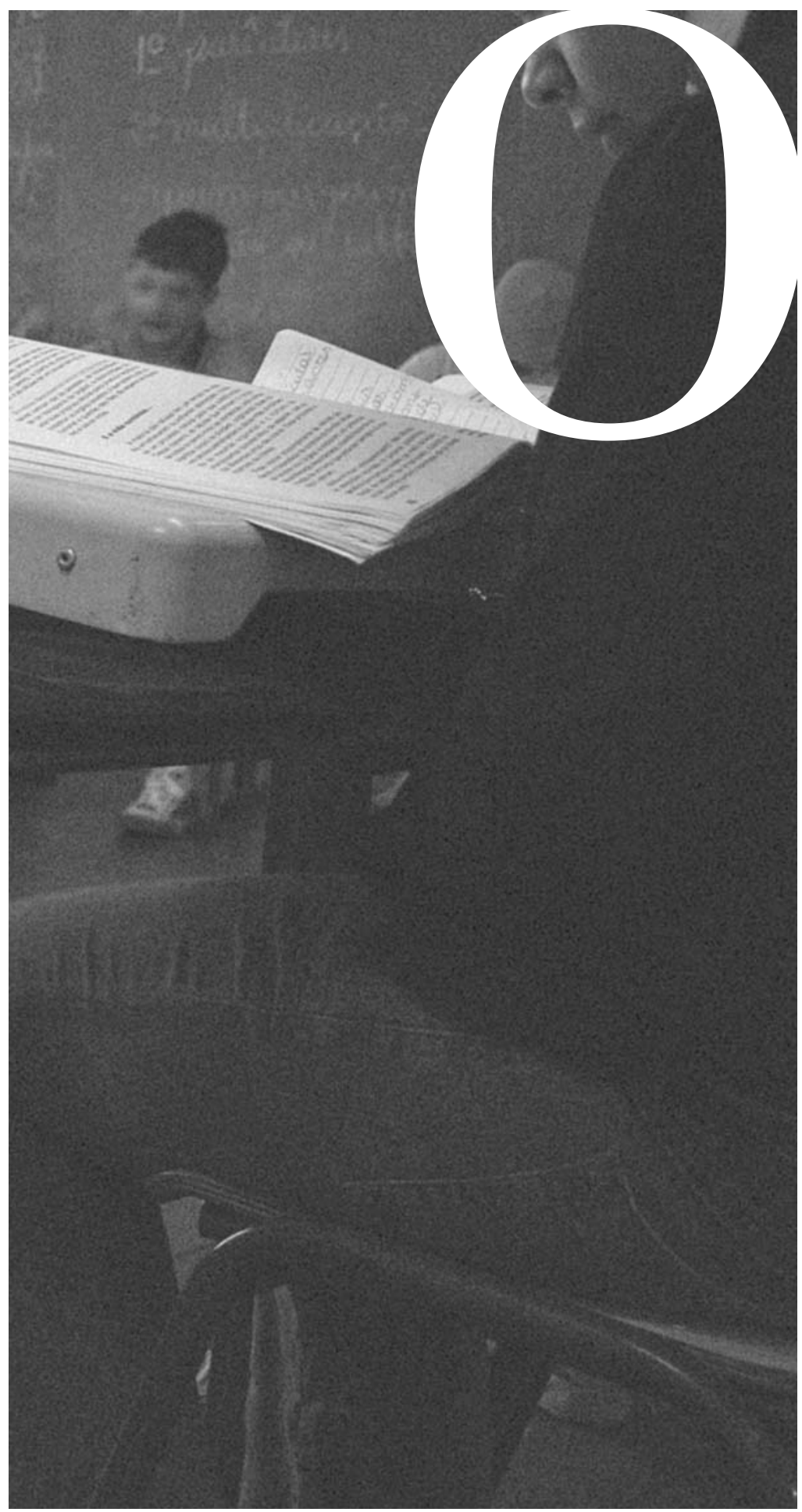

ato de avaliar era, até bem pouco tempo, talvez uma das tarefas mais óbvias do processo de ensino-aprendizagem nas escolas: tradicionalmente, por meio de prova ou chamada oral, o professor verificava "o que ficou" do conteúdo "passado aos alunos". A exigência da média sete "para passar" garantia que o aluno tinha "retido" $70 \%$ do total ensinado, ou seja, o suficiente para que se considerasse que ele aprendeu a maior parte do conteúdo.

Então, por meios quantitativos e de modo extremamente simples, solucionava-se a grande questão, em tese, resguardando objetividade, precisão e neutralidade. Aliás, esses mesmos critérios deveriam estar presentes nas respostas dos alunos, que se constituía em um processo de "corta e cola" dos textos usados pelo professor ou do material didático selecionado para as aulas: a memorização era o instrumento básico para se aprender.

Até aí, nada de novo. Sabemos que essa prática é resultante do pensamento positivista que foca quantidade e produto, verificados ao final de um processo. Caracterizava-se, assim, um modelo educacional tecnicista em que os resultados e comportamentos deveriam ser claramente (entenda-se: objetivamente, sem dúvidas ou julgamentos de valor) observáveis e medidos com precisão para se promover a eficiência.

A visão de educar, portanto, calcava-se no que Luckesi (1998) denominou de "pedagogia do exame", responsável até hoje pela preocupação maior dos alunos: "passar na prova, tirar nota boa", contribuindo assim para o desenvolvimento de indivíduos submissos ante o papel autoritário, classificatório e excludente da avaliação (Hadji, 1994, 1997; Luckesi, 1998; Santos, 2003). Avaliação significava um veredicto dado ao aluno, uma vez que "a prova ou a-prova ou re-prova" (Romero, 2004, p. 28).

* TÂNIa Regina de Souza Romero é doutora em Lingüística Aplicada e Estudos da Linguagem pela Pontifícia Universidade Católica de São Paulo. Professora de graduação e pós-graduação em Lingüística Aplicada da Universidade de Taubaté e do curso Avaliação na Visão Sociocultural- PUC/SP - COGEAE. 
Os verbos estão no passado, mas não se pode deixar de lembrar que muitos professores, assim como coordenadores e diretores de escolas públicas e particulares, continuam a praticar e incentivar esse tipo de avaliação, acreditando ser esta a orientação oficial.

Lembre-se, entretanto, que há documentos - como a LDB, Lei 9394/96, Deliberação CEE 9/97 e Indicação CEE 8/97, Normas Regimentais Básicas (Parecer CEE 67/98) e os Parâmetros Curriculares Nacionais (Brasil, 1998) - em que a avaliação é concebida como contínua e qualitativa, um elemento que integra a aprendizagem e o ensino, portanto, destinada a ser processual, para possibilitar a conscientização das dificuldades dos alunos pelos professores e pelos próprios alunos, de modo a orientar (re)planejamentos e estar a serviço do desenvolvimento de aprendizagem, renegando seu caráter punitivo e excludente.

Não acredito, em absoluto, que prosseguir com uma prática considerada hoje inadequada se deva à má vontade dos educadores. É muito difícil mudar, pois, como nos lembra Bourdieu (1989), interiorizamos conjuntos de estruturas que refletem as condições sociais que adquirimos em situações vivenciadas em nosso percurso histórico. Ou seja, precisamos fazer um esforço muito grande para deixar de agir como estamos acostumados, para adotar (e acreditar em!) novas formas de ação das quais temos pouca (e, muitas vezes, nenhuma!) referência.

Pois bem, o paradigma mudou: queremos alunos que saibam se expressar, colocar e defender seus pontos de vista, cuidadosamente argumentados, levando em consideração posições divergentes em um mundo de múltiplas verdades coexistentes que, de repente, expandiu-se e está, em tempo real, em nossa casa, ao alcance de uma tecla.

Precisamos de sujeitos críticos, conscientes do mundo em que vivem e alertas, para não se deixarem modelar passivamente diante de um discurso em que prevalecem interesses econômicos e políticos, "fundado em um pensamento único, pautado pela globalização" (Moita Lopes, 2003, p. 31). A pergunta que se faz é: como conseguir isso?

\section{Avaliando a avaliação}

Podemos iniciar uma tentativa de resposta a esta candente questão salientando que avaliação, na perspectiva sociocultural, que hoje orienta os parâmetros educacionais em voga (a exemplo dos Parâmetros Curriculares Nacionais, divulgados nacionalmente no final do último século), é entendida como parte inerente do pro-

\section{...a avaliação dá subsídios} para o professor, a escola, a comunidade, a família, o aluno encaminharem o desenvolvimento, levando em conta as premências sociais
de nosso tempo.

cesso ensino-aprendizagem. Isso equivale a dizer que 0 foco de nossa questão não é a avaliação em si, e sim a prática pedagógica, percebida como um processo interativo em que se avalia para melhor se (inter)agir: a avaliação dá subsídios para o professor, a escola, a comunidade, a família, o aluno encaminharem o desenvolvimento, levando em conta as premências sociais de nosso tempo. Com isso, todos os envolvidos no processo são igualmente aprendizes.

Salienta-se aqui a necessidade de um esforço coletivo - pouco ou nada adiantarão esforços isolados. Busca-se uma mudança para que se cultive uma cultura de aprendizagem que sirva como base para se entender a vida, engajar-se nela, saber se colocar diante dela e transformá-la, em consonância com as discussões de Paulo Freire (1970).

Neste enfoque, deve-se procurar instaurar um clima de confiança em sala de aula, em que não cabem, por exemplo, os "testes-surpresa" para "pegar o aluno desprevenido". Se o aluno e o professor trabalham em colaboração mútua, eles se vêem como aliados, não como ameaça. Então, também se entendem os erros e as tentativas como partes do processo de aprendizagem e conscientização, além de incentivo à interação constante, com o discurso do professor voltado para a orientação.

Em consonância com essa visão, está a idéia de que ser justo não significa dar exatamente o mesmo teste ou tarefa para todos os alunos. Ao contrário: é preciso levar em conta que diferentes alunos têm interesses, compreensão, motivação, vivência e envolvimento também diferentes em relação a determinados tópicos e disciplinas.

Ao professor, não se restringe mais a tarefa de só ensinar conteúdos. A ele, cabe propor desafios, e, ao mesmo tempo, dar os instrumentos ao aluno para lidar com eles, enfatizando o desenvolvimento de suas habilidades ou estratégias, tanto diretas quanto indiretas.

Dentre as estratégias diretas, segundo destaca Rebecca Oxford (1990, p. 17, apud William e Burden, 1997, p. 153), encontram-se as de: 


\section{a. memória}

como criar imagens e sons, organizar material por categorias, fazer relações mentais, revisar, criar mnemônicos;

\section{b. cognição}

como praticar, receber e enviar mensagens, analisar e raciocinar, criar estruturas facilitadoras;

\section{c. compensatórias}

como inferir de maneira inteligente ou superar limitações para falar e escrever.

As três estratégias indiretas, elencadas pela autora, são:

\section{a. metacognitivas}

como planejar o tempo de estudo e auto-avaliar progressos e conquistas;

\section{b. sociais}

como fazer perguntas, trabalhar em colaboração com outros;

\section{c. afetivas}

como diminuir a ansiedade, encorajar-se e confiar em si.

Um esforço inicial para realizar a mudança é o exame da própria prática avaliativa, numa reflexão crítica direcionada inicialmente a se entender os princípios e crenças que a regem. Em cursos dedicados a discutir a avaliação, seguindo os passos da educadora Maria Antonieta Alba Celani, percebemos que o ponto de partida para a transformação deve ser a prática.

Assim, é fundamental que o professor, junto com seu grupo institucional, inicie o processo de transformação tentando entender os princípios que fundamentam sua prática para, somente depois, empenhar-se no processo dialético com outras fundamentações teóricas. Para orientar o processo de reflexão crítica, partindo-se da análise de um instrumento (ou conjunto de instrumentos) de avaliação, são oferecidas, a seguir, algumas sugestões que retomam as questões até aqui discutidas.

Por meio das seguintes perguntas, entendemos que é relevante verificar se o instrumento - ou o conjunto de instrumentos - de avaliação:

1. É coerente com os princípios de ensino-aprendizagem adotados pela instituição: sua instituição considerase construtivista, socioconstrutivista, por exemplo?

2. Reflete o projeto político-pedagógico da instituição: a ação educacional direciona-se ao desenvolvimento de quais características no educando? Qual é a missão a que a Instituição se propõe? As ações didático-pedagógicas convergem, direcionam-se a este fim?

3. É parte integrante e intrínseca do processo educacional, ou seja: faz parte do processo de ensino-aprendizagem contínuo ou é colocado de forma isolada, como verificação de um produto final?

4. Destina-se a verificar necessidades e/ou interesses dos alunos, ou seja: tem a função de orientar um planejamento negociado?

5. Serve para se saber quais são os conhecimentos prévios dos alunos: esse tipo de instrumento de avaliação estaria atuando como iniciador de interação significativa?

6. É válido para se entender o processo de aprendizagem dos alunos, para que o professor possa trabalhar 0 desenvolvimento de habilidades metacognitivas, por exemplo?

7. É útil para investigar qualitativamente o entendimento que o aluno construiu? Em outras palavras, esse instrumento não deve ser construído com perguntas fechadas, exigindo respostas lacônicas?

8. Serve para averiguar a qualidade de ensino oferecido?

9. É adequado para o professor planejar sua regulação?

10. Investiga se determinada habilidade foi adquirida?

11. Examina se houve transferência?

12. Prevê uma rediscussão das questões colocadas, visando à ampliação do entendimento do item trabalhado?

13. Proporciona a auto-avaliação procedimental (relacionada ao "como fazer"), atitudinal (relacionada à maneira de a pessoa se colocar socialmente) e conceitual (referente ao conteúdo trabalhado)?

14. Trabalha com a habilidade de raciocínio?

15. Propicia ao aluno a reflexão e a expressão de sua opinião, fundamentando-a?

16. Possibilita que o aluno formule questões ou levante hipóteses?

17. Leva o aluno a analisar ou sintetizar algo?

18. As instruções são claras?

19. Os critérios são explícitos? Esta observação remete a uma política de transparência, segundo a qual o aluno deve ter um entendimento claro do que será levado em conta para avaliar seu trabalho. Esta compreensão a respeito dos critérios pode, inclusive, ajudar o aluno a avaliar seu próprio trabalho, desenvolvendo nele uma conscientização metacognitiva, auxiliada pela explicitação do professor. 
20.Engloba várias áreas do conhecimento?

21. Faz com que o aluno pesquise ou considere os pontos de vista divergentes?

22.É familiar para o aluno, ele entende como este instrumento funciona e deve ser trabalhado?

23. Ensina algo para o aluno? Se sim, o quê?

24. Ensina algo para o professor, instituição ou comunidade? Se sim, o quê?

25. Está sendo usado em momento adequado no desenvolvimento do curso ou da disciplina?

Essa listagem pode e deve ser adaptada ao contexto peculiar de cada escola. Observe-se que várias questões se sobrepõem e são, inclusive, redundantes, pois pretendem incentivar uma (re)análise cuidadosa da prática de avaliação que está sendo utilizada pelo professor ou instituição. Além disso, devemos apontar, como o leitor já deve ter percebido, que um só instrumento não será capaz de satisfazer todos os pontos indicados por esses 25 itens. Isso se explica por acreditarmos que apenas um instrumento ou poucos não coadunam com a visão de que a avaliação é parte contínua e integrante do processo de ensino-aprendizagem.

\section{Alguns exemplos para a prática}

A título de ilustração, daremos alguns exemplos de avaliações que, em conjunto com outras ações didático-pedagógicas coerentes, podem caminhar na direção do que foi discutido até aqui. Elas são contribuições de leituras diversas sobre avaliação e de professores atuantes na prática educativa.

\section{A. Meio ambiente}

1. Em uma escola da Grande São Paulo, um aluno comentou, em classe, quando estavam sendo discutidas formas de não se desperdiçar água, que a propaganda de uma marca de chuveiro, veiculada na televisão naquela época, incentivava as pessoas a se entregarem ao prazer de banhos longos. A propaganda, afirmou o aluno, estava na contramão de campanhas contra o desperdício. Aproveitando a sua contribuição, a classe resolveu pesquisar o endereço do fabricante do chuveiro para lhe enviar uma carta. A carta foi preparada pela classe toda, sob a orientação da professora de Português, que cuidou para que ela fosse respeitosa, contivesse

\section{Os portifólios possibilitam}

o desenvolvimento de aprendizagem auto-regulada, negociação de significados, processos e produtos com o

\section{professor e oportunidades de reflexão conjunta.}

o problema percebido e mencionasse o poder da mídia para influenciar as pessoas. Pedia-se ainda para que medidas fossem tomadas. Rapidamente, a propaganda foi retirada do ar.

2. Em uma escola da periferia da cidade de São Paulo, chegou a notícia de que o bairro fora escolhido para abrigar um dos lixões da área metropolitana. Preocupados com o impacto ambiental e as possíveis conseqüências sanitárias que daí pudessem advir para os moradores, os alunos debateram a questão em sala de aula e decidiram envolver a comunidade, conversar com as autoridades municipais e promover passeatas, além de chamar a imprensa para testemunhar as iniciativas. 0 lixão não foi para este bairro.

3. Uma professora de Inglês levou, a pedido de um grupo de alunas, uma música do grupo Backstreet Boys. A escolha foi contestada por outros grupos da sala que alegaram não gostar daquele tipo de música, insinuando que os componentes do grupo eram homossexuais. Estas diferenças de opinião e expressão de preconceito contra orientações sexuais consideradas "certas" deram margem a discussões frutíferas quanto à diversidade, exclusão e negociação. E, para subsidiar as discussões, foram usados outros textos, também em inglês, pesquisados na Internet pelos alunos, que falavam sobre a vida dos componentes do grupo musical, violência em consequiência de preconceitos etc.

Estes são exemplos de ações cidadãs. Segundo Clough e Holden (2002), para que isso ocorra, é necessário que a escola atue de forma que os alunos desenvolvam:

a. confiança para emitir opiniões; 
b. habilidades para reconhecer pontos de vista e/ou opiniões diferentes das suas;

c. habilidades de pensamento crítico, dialético, e argumentação embasada;

d. habilidades de colaboração e resolução de conflitos, quando discutir acordos com outros;

e. habilidade de participação democrática;

f. experiência em tomar iniciativas para conseguir mudanças.

Pode-se verificar que os três casos relatados puderam propiciar o desenvolvimento desses seis requisitos, a partir de situações reais.

\section{B. Portfólios}

Em vários níveis de escolaridade, os portfólios vêm sendo usados para a avaliação, segundo relatam Paris e Ayres (1994). Esses instrumentos têm encontrado grande respaldo de educadores por se constituírem em alternativa mais significativa a formas quantitativas de avaliação, além de, potencialmente, possibilitarem, muito além de uma amostragem estática, o desenvolvimento de aprendizagem autoregulada, o envolvimento do aluno e a negociação de significados, processos e produtos com o professor e oportunidades de reflexão conjunta.

Shores e Grace (2001) consideram os portfólios "uma coleção de itens que revela, conforme o tempo passa, os diferentes aspectos do crescimento e desenvolvimento de cada [aluno]". É importante, entretanto, ressaltam as autoras, que se estipule uma política de coleta de trabalhos consistente com o projeto político-pedagógico da instituição.

\section{Auto-avaliação}

Destacam-se, a seguir, duas contribuições de Paris e Ayres (1994, p. 78 e 83): a primeira deve ser aplicada logo após a realização de um projeto em grupo; a segunda favorece também o desenvolvimento de escrita com propósito real. 0 terceiro exemplo foi elaborado por uma profissional especialista em avaliação. Para os dois primeiros exemplos, em acréscimo, sugerimos que as produções dos alunos sejam posteriormente discutidas com o professor para que se confrontem, possivelmente, opiniões diferentes e também para orientar o processo meta- cognitivo da auto-avaliação. No terceiro exemplo, já se prevê espaço para essa interação.

\section{Auto-avaliação de projeto}

- O que você gostou do projeto?

- O que poderia ter feito com que este projeto fosse melhor?

- De que você mais se orgulha? Por quê?

- Como você se dedicou ao projeto?

- O que foi difícil?

- O que você sabe agora que não sabia antes? (Seja específico.)

- Que nota você acha que seu grupo merece neste projeto? Justifique sua resposta.

\section{Apresentação para a professora do próximo ano.}

Escreva uma carta se apresentando para a sua professora do próximo ano. Escolha seu melhor trabalho do portfólio e anexe a sua carta. Descreva seus pontos fortes como leitor e escritor, usando o trabalho anexo como referência.

\section{Com base nesta prova [de Biologia] que você acabou de fazer:}

1. Avalie sua aprendizagem.

2. Você necessita de orientação da professora? Em qual conteúdo?

3. O que você deve fazer para melhorar ou continuar melhorando o seu desempenho?

Comentários da professora:

\section{HISTÓRIA DO BRASIL}

1. Em seguimento a uma discussão sobre assinatura da Lei Áurea, assinada pela Princesa Isabel, responda: qual a conseqüência desse ato? Explique.

2. Suponhamos que você tivesse a possibilidade de viajar em uma máquina do tempo e voltasse para 1889, no Rio de Janeiro, e lá atuasse como repórter de um importante jornal. Escreva um artigo de/para jornal noticiando a Proclamação de Independência. 
Ambas as questões requerem que o aluno faça avaliações das situações apresentadas, expressese e exponha seus pontos de vista, embasando-os criticamente. São questões abertas que propiciam o desenvolvimento da linguagem e funções psicológicas superiores, em termos vygotskianos, como: pensamento abstrato, raciocínio dedutivo, capacidade de se relacionar e transferir conhecimento.

\section{E. Projeto conjunto: Geografia, História, InglÊs E INFORMÁTICA}

1. Escolha três países distintos em que a língua inglesa é falada (exceto a Inglaterra).

2. Pesquise as razões históricas da introdução da língua inglesa nestes países.

3. Pesquise as características gerais e as particularidades de cada país.

3. Faça um resumo das especificidades de cada país e compare-as.

4. Prepare um pôster para ser afixado no corredor da escola e apresentado oralmente para os colegas, resumindo sua pesquisa.

Este projeto foi realizado em duplas, com a colaboração dos professores das disciplinas envolvidas ou de um único professor-orientador escolhido pelos grupos. Os alunos foram orientados, entre outras necessidades, quanto aos instrumentos básicos de pesquisa e busca na Internet, redação e organização adequadas para o pôster. Com esta tarefa, incentivaram-se, por exemplo, a criatividade, a iniciativa de busca, a variedade de interesses, a organização de sínteses e a relação interpessoal.

\section{Algumas considerações}

A discussão, dúvidas e buscas sobre a avaliação são tão infindas, propensas ao debate e polêmicas quanto o próprio processo de ensino-aprendizagem. Não há receita pronta, um "faça assim que vai dar certo", porque a vida (seus vários prismas, significados, sentidos e premências) é multifacetada. Felizmente! Resguardase, assim, nossa ação atenta e crítica ante as nossas ações passadas e futuras como profissionais da educação, comprometidos com a missão que assumimos para nós mesmos.
Olhando por esse ângulo, estas considerações têm o propósito de instigar novas discussões e, por conseguinte, incentivar pesquisa, diálogo, reflexão.

Para finalizar, recorremos a Maria Antonieta Alba Celani (2000, comunicação pessoal). Segundo ela, a avaliação não deve se desvincular do entendimento que, na escola, "conteúdos são meios para que os alunos desenvolvam as capacidades que lhes permitam produzir bens culturais, sociais e econômicos e deles usufruir".

\section{Referências}

BOURDIEU, P. O poder simbólico. Rio de Janeiro; Lisboa: Bertrand Brasil; Difel, 1989.

BRASIL. Secretaria de Educação Fundamental. Parâmetros Curriculares Nacionais: introdução. Brasília: MEC/SEF, 1998.

CLOUGH, N.; HOLDEN, C. Education for citizenship: ideas intoaction. London: Routledge Falmer, 2002.

FREIRE, P. Pedagogia do oprimido. Rio de Janeiro: Paz e Terra, 1970.

HADJI, A. A avaliação, regras do jogo. Das intenções aos instrumentos. Portugal: Porto Editora, 1994.

LUCKESI, C. Avaliação da aprendizagem escolar. 8. ed. São Paulo: Cortez, 1998.

MOITA LOPES, L. P. A nova ordem mundial, os parâmetros curriculares nacionais e o ensino de inglês no Brasil: a base intelectual para uma ação política. In: RAMOS, L. Bárbara; RAMOS, R. de C. G. (Org.). Reflexão e ações no ensinoaprendizagem de línguas. Campinas: Mercado de Letras, 2003.

PARIS, S. G.; AYRES, L. R. Becoming reflective students and teachers with portfolios and authentic assessment. Washington: American Psychological Association, 1994 .

PERRENOUD, P. Avaliação: da excelência à regulação das aprendizagens - entre duas lógicas. Porto Alegre: Artmed, 1999.

ROMERO, T. R. S. Os desafios da avaliação: contribuições da visão sociocultural. Contexturas: ensino crítico de língua inglesa, São Paulo, Apliesp (Associação de Professores de Língua Inglesa do Estado de São Paulo), n. 7, $2003 / 2004$.

SANTOS, P. S. Avaliação: representações da instituição, dos professores e alunos. 2003. Dissertação (Mestrado) - LAEL, PUC-SP, São Paulo, 2003.

SHEPARD, L. The role of assessment in a learning culture. Educational Researcher, V. 2, n. 7, p. 4-14, out. 2000.

SHORES, E.; GRACE, C. Manual de portfólio: um guia passo-a-passo para o professor. Porto Alegre: ArtMed, 2001.

WILLIAM, M.; BURDEN, R. L. Psychology for language teachers. Cambridge: Cambridge University Press, 1997.

\section{Para saber mais}

Curso de avaliação na visão sociocultural, no COGEAE, PUC-SP, e no site: «www.pucsp.br/cogeae».

\section{Notas}

1 Segundo Perrenoud (1999, p. 89), regulação é a ação intencional do professor ou educador, "cuja intenção seria determinar ao mesmo tempo o caminho já percorrido por cada um [o aluno] e aquele que resta percorrer com vistas a intervir para otimizar os processos de aprendizagem em curso".

2 Diz-se que houve transferência de conhecimento quando se é capaz de usar o conhecimento adquirido em situações novas, o que requer flexibilidade, novas relações e generalizações (Shepard, 2000). 